\title{
ESTATUTO ONTOLÓGICO DEL EMBRIÓN HUMANO COMO PERSONA. UNA PERSPECTIVA DESDE LA INVESTIGACIÓN BIOLÓGICA EN AMÉRICA LATINA
}

\begin{abstract}
Álvaro Olivo Yépez ${ }^{1}$ Pascual Linares Márquez¹, Ana Isabel Suárez Guerrero¹, Ana María Aguirre Guzmán ${ }^{1}$

Resumen: La utilización de embriones humanos en la investigación biológica ha generado un debate ético desde la discusión ontológica, en relación a si se puede o no considerar al embrión persona humana. En este artículo se análiza el estatuto ontológico del embrión humano desde una perspectiva biológica, considerando las principales líneas de investigación que lo intervienen en América Latina. Adcionalmente, revisamos el aporte desde el estatuto legal del embrión humano en esta región y la postura desde la formalidad de la investigación cientifica en el cuidado de su utilización. Consideramos finalmente que en América Latina no se ha abordado de manera profunda la discusión en torno al estatuto del embrión humano como persona, quedando la discusión en una dimensión biológica.
\end{abstract}

Palabras clave: embrión humano, persona, América Latina, bioética del embrión

Ontological statute of the human embryo as a person. A perspective from biological research in Latin America

Abstract: The utilization of human embryos in the biological research has generated a bioethical debate from the ontological point of view about whether or not to consider the embryo as a human person. This paper review the ontological statute of the human embryo from a biological perspective considering the principal lines of investigation in Latin America. Complementary to discussion we check the contribution from the legal statute of the human embryo and the position from the formal scientific research in his utilization. Finally, we consider that, in Latin America, the discussion has not been approached in a deep way about the statute of the human embryo as person, staying the discussion in a dimension of the biological thing.

Key words: human embryo, person, Latin America, bioethics of the embryo

Estatuto ontológico do embriáo humano como pessoa. Uma perspectiva a partir da investigaçáo biológica na América Latina

Resumo: A utilização de embriōes humanos na investigação biológica tem gerado um debate ético a partir da discussão ontológica, com relação a se deveria ou não considerar o embrião pessoa humana. Neste artigo se analisa o estatuto ontológico do embriāo humano a partir de uma perspectiva biológica, considerando as principais linhas de investigação de intervenção no embrião na América Latina. Adicionalmente, revisamos a contribuição a partir do estatuto legal do embriáo humano nesta região e a postura a partir da formalidade da investigação cientifica no cuidado de sua utilização. Consideramos finalmente que na América Latina não se tem abordado de maneira profunda a discussão em torno do estatuto do embrião humano como pessoa, tornando-se a discussão uma dimensão biológica.

Palavras-chave: embrião humano, pessoa, América Latina, bioética do embrião

\footnotetext{
${ }^{1}$ Facultad de Biología, Universidad Veracruzana, México

Correspondencia: palinares@uv.mx
} 


\section{Introducción}

La investigación científica ha posibilitado la intervención del cuerpo humano en sus diferentes estadios del desarrollo biológico, y es la intervención de embriones una práctica desarrollada en la búsqueda de posibilidades eugenésicas, cura a enfermedades hereditarias y, en mayor medida, para enfrentar problemas de reproducción asistida. Esta última se encuentra estrictamente regulada en algunos países. Sin embargo, no es la constante. En la mayoría de los países en desarrollo existe poca claridad al momento de considerar si el embrión humano es persona o no. De la misma forma, hay una carencia de legislación en relación a la intervención científica del embrión humano con fines médicos, o en la reproducción asistida.

Particularmente, en la región de América Latina se inicia la intervención de embriones humanos desde la investigación científica sin considerar las condiciones culturales y legales para abordar de una manera definitiva y a fondo la posibilidad de considerar el embrión como objeto de estudio, así como los límites y consecuencias en la intervención del mismo. Desde este panorama, la discusión del estatuto ontológico del embrión humano, en tanto persona, es un problema pendiente de analizar y normar en Latinoamérica, considerando que, de no hacerlo, la intervención y transformación del embrión puede generar problemas de carácter científico y ético que pueden derivar en el abuso o en la obstrucción de la investigación científica.

Desde la perspectiva ética, los pronunciamientos a favor y en contra de la intervención del embrión humano están polarizados: una parte de la comunidad científica se pronuncia por aplicar las técnicas diversas a los embriones humanos en cualquier estadio de desarrollo, siempre y cuando los resultados lo justifiquen. Esta postura simplista, que ubica al embrión como un ente al que no se le puede atribuir la condición de "persona humana", lo pondera como una "cosa", sin considerar su valor mas allá del objeto de estudio. En contraposición, existe otro sector que condena radicalmente la utilización del embrión en la investigación, bajo argumentos que atribuyen a este el estatuto de persona humana, fundado en argumentos biológicos deterministas, como la presencia de siste- ma nervioso, la formación de extremidades en el desarrollo embrionario o la fijación en la cavidad uterina. Estas posturas con frecuencia no están acompañadas de una revisión normativa, en que la opinión de la sociedad, representada en una heterogeneidad de modos de vida, creencias religiosas, costumbres y derechos humanos, sea considerada; más bien se generan desde la academia.

En Latinoamérica es evidente que la discusión ontológica acerca del embrión humano es básica o nula. La incertidumbre de la valoración moral del embrión desde su utilización; i.e. los aspectos inherentes a su generación in vitro y la relación de estos con el estatuto de la persona humana, se ha analizado poco. Esto ha derivado en una perspectiva ambigua del tema, con un vacío normativo que permite el libre manejo en la intervención del embrión humano.

Abordamos en este trabajo un análisis del estatuto ontológico del embrión humano en América Latina, considerando que predomina una argumentación biológica para fundamentar la intervención tecnocientífica, y que esta no es suficiente para definir criterios de manejo y utilización de los embriones en las diversas líneas de investigación que hoy se desarrollan en la región. Revisaremos las posturas respecto de la ubicación ontológica del embrión humano, a partir de una línea cronológica, haciendo énfasis en autores contemporáneos que nos permitan, más allá de la comparación, reconocer cómo se considera ontológicamente en el presente al embrión humano. Detallaremos las líneas de investigación que utilizan al embrión como objeto de estudio y haremos una revisión del marco legal en países de América Latina. Consideraremos la situación que se presenta en México desde el marco legal. Esto nos permitirá contar con un panorama del estado de la discusión y las necesidades de adentrarnos a un análisis profundo y complejo respecto del estatuto de persona humana imputada al embrión.

\section{El embrión humano, concepto y utilización}

Una posible definición biológica del embrión humano apunta a que este se inicia desde la fecundación hasta la formación del feto y se ubica aproximadamente en la octava semana de gestación(1). Sin embargo, esta no es la única defini- 
ción, existen documentos y autores que manejan a esta realidad biológica de diferente forma. Un ejemplo de esto es la Ley General de Salud vigente en México, misma que considera al embrión como el conjunto de células resultado de la concepción y lo ubica temporalmente a partir de esta y hasta la décimosegunda semana de gestación(2). Por otro lado, en la opinión de Velásquez, el embrión humano transcurre por una serie de etapas de desarrollo que inician con la fecundación y finalizan en la segunda semana de gestación con el surgimiento de la línea primitiva del aparato nervioso, lo cual sucede instantes después de que el embrión se implante en el útero(3). Esto hace notar que, además de las diferencias en la definición del embrión humano, los autores proponen que el inicio de la vida del embrión ocurre desde la fecundación; es notable también que, entre estos autores, existe una diferencia en el tiempo señalado como limitante de la etapa embrionaria.

El embrión humano ha sido objeto de estudio en términos descriptivos con la embriología. Sin embargo, es el nacimiento de Brown lo que cambió la perspectiva de estudio con la que se veía al embrión humano. Brown fue el primer bebé logrado por fertilización in vitro(3). Con ello se comprobó que la fecundación de un óvulo por un espermatozoide se puede llevar a cabo fuera del seno materno y por medio de una técnica de laboratorio, algo hasta entonces no considerado en el proceso de generación de un ser humano. Este evento representa un hito en la intervención de la ciencia sobre el ciclo biológico del ser humano. Se plantea entonces que no todos los hombres en este planeta se podían y debían ajustar a la fecundación en términos biológicos naturales: algunos podían iniciar su ciclo vital en un laboratorio.

Este logro tecnocientífico despoja al embrión humano de su envoltura meramente biológica y lo convierte en un objeto de estudio bajo una perspectiva nueva de investigación e intervención. Se inaugura así la transformación del embrión humano en posibilidad desde la biología del desarrollo, medicina regenerativa y reproducción asistida.

La reproducción asistida hace uso del embrión humano como objeto de investigación, con la finalidad de ayudar a individuos con problemas de esterilidad para, desde la fecundación in vitro, concebir un hijo(4). En este sentido, la reproducción asistida actúa directamente sobre los elementos necesarios en la generación del embrión humano, para facilitar la procreación de un embrión.

Otra línea de investigación es la medicina regenerativa. En esta se interviene al embrión utilizándolo como materia prima para la obtención de células madre, las cuales pueden ser manejadas en el tratamiento de enfermedades y regeneración de tejidos u órganos(5).

Para llevar a cabo intervenciones desde estas líneas de investigación se aplican técnicas diversas, dependiendo de las necesidades y los productos a obtener. Sin embargo, de manera general, es la técnica de la fertilización in vitro la más utilizada, ya que mediante esta se generan embriones viables para su implantación en el vientre materno(6).

Se puede considerar también como técnica general la crioconservación de embriones humanos, cuyo objetivo es conservar a los embriones sobrantes de la fertilización in vitro (que no hayan sido utilizados en reproducción asistida), a temperaturas bajo cero. Con ello se asegura la posibilidad de emplearlos para estudios posteriores(7).

La crioconservación de embriones ha sido un destino alterno para los embriones sobrantes de la fertilización in vitro, así como de cualquier otra técnica de reproducción asistida. Sin embargo, algunos de estos embriones no vuelven a ser utilizados en técnicas futuras, lo que permite su donación a la investigación. Es el desecho de los mismos, al no ser útiles en la reproducción asistida, lo que genera el debate sobre la cosificación del embrión, la pertinencia de su uso y, por ende, la búsqueda de su estatuto ontológico como persona humana, intentado con ello delimitar y regular la utilización del embrión en la investigación científica.

\section{Conceptos de persona en la filosofía contempo-} ránea

En la filosofía contemporánea, autores como Engelhardt, Álvarez y Singer, aparte de dar un criterio acerca de cómo se puede identificar a la 
persona desde componentes particulares, añaden una clasificación de la misma en la que podemos encontrar al embrión humano(8).

Engelhardt, por medio de su criterio de "capacidad moral", identifica al embrión como un ser humano sin moral, como señalaba ya Kant; el embrión no está dentro de la sociedad y, por tanto, no puede tener moral(9). Álvarez clasifica al embrión humano como solo un individuo de la especie humana(10) y al no dar más criterios para fundamentar su clasificación, la misma es vaga. Por otra parte, Singer acusa que el embrión humano no es una persona, pues carece de racionalidad y conciencia, pero que se puede considerar humano(11).

Los anteriores autores están de acuerdo que el embrión entra más en la categoría de humano que en la de persona. Ahora bien, a diferencia de ellos, Harris no da una clasificación de persona. Para él, lo importante en la consideración de persona es poder valorar su existencia, cualidad que puede aparecer y desaparecer en cualquier momento, lo cual sugiere que es parte de un flujo continuo. Desde este enfoque señala la existencia de prepersonas, personas y expersonas, y el embrión humano se ubicaría en las prepersonas(12).

\section{Embrión, persona o ser humano}

Sin embargo, las dificultades planteadas llevan a preguntarse: ¿si el embrión humano no es una persona, entonces qué es? Para responder a esta incógnita hemos revisado las teorías de hominización, mismas que determinan, bajo sus estatutos, que el embrión es un ser humano; no obstante, cada teoría establece un distinto factor de tiempo para dictaminar la presencia de un nuevo ser humano.

Los argumentos de cada teoría son diferentes entre sí. La teoría de la hominización inmediata(13) apunta que el embrión es un ser humano desde el momento de la fecundación, porque es desde entonces que empieza a ser un ente organizado y no deja de serlo en su faceta de desarrollo. Por otra parte y en contrapostura, la teoría de la hominización retardada(13) sugiere que el embrión no es humano hasta que presenta las funciones o estructuras necesarias para desarrollar las cualidades distintivas del ser humano, como el pensamiento, la conciencia o la racionalidad, las cuales surgen después de la segunda semana de gestación, con la aparición de la línea primitiva del aparato nervioso(14).

Estas teorías se fundan argumentativamente en nociones biologicistas, lo cual puede cuestionarse, por su matiz reduccionista o simplista. Desde otro enfoque, se considera problemático el hecho de plantear conceptos como el de "persona" para distinguir o clasificar a los seres humanos. Corremos el riesgo de que una categoría como esta dote de derechos a ciertos seres humanos y se los quite a otros tantos(15).

Entre estas concepciones, podemos considerar la noción que plantea Habermas, quien establece que la "inviolabilidad de vida" es una característica de las personas que se adquiere al nacer y que es la facultad de vivir. Así, la persona se encuentra impedida de realizar acción alguna que atente contra su vida; la "indisponibilidad de vida", en cambio, es una facultad que tienen los no nacidos (embriones o fetos), para quienes su vida puede estar sujeta a diversos intereses de cualquier índole(16). Este postura habermasiana refuerza las intervenciones practicadas con el embrión humano con fines de investigación u otros de índole económica. Consideramos que, cuales sean los tipos de utilización e intervención del embrión, estos deben establecerse de forma independiente de catalogarlo como persona o no, más bien porque al embrión debe considerársele como un ente perteneciente a lo humano y, por lo tanto, en consideración a ello, se deben marcar criterios con bases biológicas, filosóficas y socioculturales(17).

\section{Utilización de embriones humanos}

La investigación con embriones es una realidad en diversas partes del mundo. Estas se fundan en perspectivas que van desde lo simplista hasta lo complejo, sin dejar de lado las posturas religiosas. Encontramos entre ellas a la ética utilitarista, la que califica como moral actividades que tengan como meta dar un beneficio a la humanidad y, en este sentido, se toleran las intervenciones dañinas, siempre y cuando estas no sobrepasen el beneficio que se persiga(18). Este argumento justifica la utilización de embriones en la investigación 
científica, considerando la destrucción de los no utilizados o sobrantes.

Otro punto de vista sobre la utilización de embriones humanos es el debate en torno al uso del diagnóstico genético preimplantatorio (DGP), el cual se aplica en la reproducción asistida(19). Este tiene como finalidad determinar los embriones viables para su desarrollo, con base en un diagnóstico genético, con fines terapéuticos, procurando descartar los embriones que puedan ser proclives a alguna enfermedad, deformación o cualquier tipo de anomalías.

Pese a que esta técnica exhibe un fin benéfico, la controversia de su uso se basa en que dicho diagnóstico también arroja datos sobre genes que pueden dar origen a rasgos distintivos(19), lo que puede tentar a la selección de embriones con base en criterios personales de selección. Esta técnica se considera aplicable solo para una finalidad terapéutica en el caso de enfermedades graves.

Existe una marcada preocupación moral sobre cómo actuar ante estos entes (20). Sin embargo, la determinación del estatuto embrionario se avala desde una posición moral determinada o alterada para reconocer al embrión humano, así como su consideración ontológica(20). Se piensa que el debate sobre el estatuto del embrión es un tema complejo, que necesita una revisión amplia y cuidadosa, desde un análisis profundo de los límites y criterios en juego, para establecer el estatuto embrionario de persona o individuo(21).

\section{Normativa en América Latina}

Es en esta región donde se encuentra una gran controversia, pero es también aquí donde no se han establecido criterios legales acerca del estatuto del embrión humano, la utilización del mismo y las medidas institucionales en juego.

En los países latinoamericanos, el estatuto del embrión humano descansa en el hecho de ser persona. Esto se refleja en los códigos civiles de varios países, como es el caso de Argentina, donde establece que "la existencia de la persona comienza con la concepción en el seno materno". Así es que estos individuos se consideran personas por nacer, y pueden adquirir derechos desde la concepción, como si ya hubiesen nacido.

En el caso de Bolivia, su código civil señala que "la existencia de la persona empieza desde el nacimiento, pero al no nacido se repunta vivo para todo lo que le favorezca" (22). Este apartado es similar a lo manifestado en el código civil costarricense, que agrega el periodo de "300 días antes del nacimiento para considerarlo como nacido en todo lo que le beneficie" (23). Por otro lado, en Colombia se realiza la categorización de persona en tanto natural y legal, siendo la primera cualquier individuo perteneciente a la especie humana y la segunda surge al nacer vivo. Sin embargo, en protección al no nacido, el código civil manifiesta que su protección será dictaminada por un juez cuando se considere necesario(24).

Estos ejemplos son enfocados a la consideración del embrión humano como persona dentro del marco jurídico de algunos países latinoamericanos que, pese a no dar una aclaración para los criterios mencionados, se puede entender al embrión de forma ambivalente: como no nacido y como persona existente para todo lo que le beneficie. Los periodos de tiempo para su protección antes del nacimiento no están del todo establecidos, como es en el caso de Costa Rica y, más aún, en este mismo sentido, no se le considera cuando puede ser afectado. La utilización de embriones en investigación científica de América Latina es una realidad, más allá de contar con medidas jurídicas claras en cuanto a su estatuto ontológico y su reglamentación, se le considere persona humana o no.

Se puede mencionar los esfuerzos en establecer una regulación al respecto, como la Ley de Fertilización Asistida de la provincia de Buenos Aires, en Argentina, la cual, en sus nueve artículos, tiene como objetivo la regulación de las técnicas de reproducción asistida por medio del reconocimiento de la infertilidad como una enfermedad, misma que estará sujeta a la cobertura médica asistencial, regulada por la autoridad gubernamental correspondiente, creándose para ello el Consejo Consultivo Médico de fertilización asistida, dictaminado por su propio reglamento y que, en conjunción con un comité asesor de bioética interdisciplinario, atenderán las prestaciones que se ofrezcan a las parejas beneficiarias(25). 
Esta ley, si bien no tan específica, trata de atribuir al Estado la regulación de las técnicas de reproducción asistida, lo cual provee de un cuidado en la forma de realizar las investigaciones con embriones humanos. Otros países, como es el caso de Colombia, cuentan con una propuesta de Ley sobre Reproducción Asistida, que tiene como objeto normar los métodos científicos de procreación asistida. Entre estas normas tiene importancia el apartado de beneficiarios de las técnicas de procreación asistida: pareja heterosexual de mayores, cuya edad no presente riesgos ante el proceso de gestación, salud o formación integral del nuevo ser; también manifiesta que dicha pareja, debe de estar unida por matrimonio o unión marital(26). Se establecen prohibiciones para las técnicas de procreación asistida, entre las que destacan la de mantener in vitro óvulos fecundados que rebasen los catorce días, comerciar con preembriones y sus células, elección del sexo, clonación, entre otras. Este proyecto de ley podría considerarse como una legislación referente a la reproducción asistida, así como una de las primeras en realizarse en América Latina.

\section{Normativa mexicana}

El país no cuenta con una legislación especializada sobre el embrión humano; sin embargo, podemos ajustarnos al criterio de no nacido, en conjunción con los demás países latinoamericanos.

No obstante, al realizar un análisis a la Ley General de Salud, se puede notar una indefinición o poca profundidad sobre la utilización de los embriones humanos, siendo la primera pauta al respecto la definición de embrión que se expresa como el conjunto de células resultado de la fecundación, desde la misma hasta la duodécima semana de gestación(2). Por otro lado, dos apartados posteriores mencionan que podrían considerarse para establecer manejo de los embriones humanos, siendo el primero de estos apartados el de donaciones. Este señala que para llevar a cabo la donación de material biológico como células, tejidos, órganos o gametos, entre los cuales contaríamos a los embriones, se necesita un consentimiento informado. En el segundo caso, el apartado sobre trasplantes manifiesta que está prohibida la utilización para cualquier finalidad de tejidos embrionarios o fetales producidos de abortos in- ducidos(2); sin embargo, no incluye otro origen de tejidos embrionarios, como la técnica de la fertilización in vitro.

Dentro de la Ley General de Salud se encuentra el reglamento general de salud en materia de investigaciones, que establece generalidades sobre las investigaciones que se pueden realizar con seres humanos(27). Uno de los postulados más importantes señala que se necesita un consentimiento informado sobre los riesgos y beneficios de la investigación que se plantee realizar en mujeres embarazadas, nacimientos vivos o muertos, así como en menores, en los que podríamos considerar al embrión humano, por no aclarar a qué se referiría la ley como menor de edad.

Además de esta pauta, se puede considerar como importante y específico un apartado en el cual se señala que solo serán aceptables las investigaciones de reproducción asistida si se usan para solucionar problemas de esterilidad(27). Esta parte del reglamento, si bien es muy general y podría cubrir todas las técnicas de reproducción asistida, limita el uso de las mismas, considerando que México carece de una reglamentación especializada sobre la utilización de embriones humanos para la investigación.

\section{Discusión y conclusiones}

Es pertinente señalar que el abordaje del problema para determinar si el embrión humano se puede considerar una persona humana es complejo. Sin embargo, también debemos reconocer que para esta determinación no son suficientes los argumentos desde la biología. La aportación de esta disciplina en relación con los aspectos funcionales y morfológicos del desarrollo embrionario son claros, pero considerar estos aspectos para fundar, desde la funcionalidad o morfología, criterios que determinen la esencia de la persona humana es inadecuado. Más aún, considerar la aparición de una estructura o los tiempos de desarrollo embrionario para atribuir al embrión una identidad es tan relativo que deriva en una miscelánea de posibilidades.

Así, más allá de la consideración del embrión como persona humana, es innegable que la intervención es este desde la investigación científica 
nos ha permitido entender enfermedades y buscar tratamientos, sobre todo en la biología de la reproducción. Lo que resulta fuertemente discutible es la modificación del ser humano a través del manejo del embrión y, lo más preocupante, la trivialidad en la utilización de embriones humanos desde la aplicación de técnicas como la fertilización in vitro, en la que se toman libertades en el número de embriones que se generan y en la subsecuente destrucción de los mismos al no ser utilizados.

Al denominar al embrión humano como persona encontramos como constante que los criterios tienden a ser reduccionistas. Se contempla una porción limitada del conocimiento para abordar un fenómeno por demás complejo. Como ejemplo, podemos señalar la postura de Singer(11) frente al concepto de persona; plantea que este se fundamenta en la racionalidad y la conciencia.

La construcción de persona humana es un complejo que va más allá de lo biológico; plantea en su complejidad una genética desde la especie, pero moldeada en complementariedad con el ambiente natural y cultural. Desde el ámbito científico, la ponderación de persona será un complejo determinado no por una disciplina, sino en la consideración de su composición multifactorial. Será necesaria una postura transdisciplinar, que considere elementos que la biología pueda aportar.

La investigación con embriones es una realidad en América Latina; sin embargo, la discusión es vaga e incierta y debe aclarar la postura ontológica desde los expertos, desde las líneas de investigación en desarrollo y del propio Estado, para fundamentar una regulación pertinente desde la intervención científica y cualquier otra índole de intervención.
La no definición de postulados ontológicos nos sitúa en la trivialidad del embrión humano como objeto de estudio, debido a que la diversidad de criterios es demasiado amplia. Es necesario que los protocolos y las restricciones en la aplicación de técnicas y métodos utilizados sean precisos y que se señale desde las líneas de investigación qué se entiende por embrión humano. De no hacerlo, se corre el riesgo de caer en una simple manipulación mercantilista con base en el manejo de embriones.

Las líneas de investigación en reproducción asistida y diagnóstico genético preimplantatorio son ampliamente difundidas hoy. En el espacio público se tiene una concepción ligera de los alcances de estas líneas y se consideran herramientas generadoras de hijos. En América Latina, la falta de debate profundo, las creencias excluyentes y las posiciones sensacionalistas de los medios de comunicación son la cara contraria de una postura responsable en la intervención desde la ciencia, en particularmente en el ámbito clínico(28). Esta situación sienta bases para una visión sobre el embrión humano en términos de cosa(19), sujeta a intereses de terceros, como señala Habermas con el término "indisponibilidad de vida"(16). 
Estatuto ontológico del embrión humano como persona - Álvaro Olivo, Pascual Linares, Ana I. Suárez, Ana M. Aguirre

\section{Referencias}

1. Vázquez R. Experimentación con embriones y procreación asistida. En González J. (coord.) Dilemas de bioética. México: Fondo de Cultura Económica; 2007.

2. México. Ley General de Salud. 2012 (consulta 7 de diciembre de 2012). Disponible en: http://www.diputados.gob.mx/ LeyesBiblio/pdf/142.pdf

3. Velásquez J. Del homo al embrión: ética y biología para el siglo XXI. Madrid: Editorial Gedisa; 2003.

4. Hurtado F. Indicaciones de las técnicas de reproducción asistida. Clases de residentes. Granada, España: Universidad Virgen de las Nieves; 2008.

5. Hernández P. Medicina regenerativa y aplicación de las células madres: una nueva revolución en medicina. Revista Cubana de Medicina 2011; 50(4): 338-340.

6. Aibar L, Martínez L. Fecundación in vitro. Clases de residentes. Granada, España: Universidad Virgen de las Nieves; 2011.

7. Guzmán L, Pella R, Arguello B, et al. Crioconservación de embriones al tercer día de desarrollo in vitro. Revista Peruana de Ginecología y Obstetricia 2008; 54: 117-120.

8. Burgos J. Persona versus ser humano: un análisis del esquema argumentativo básico del debate. Cuadernos de Bioética 2008; XIX(3): 433-447.

9. Engelhardt T. Fundamentos de bioética Barcelona: Paidós; 1995.

10. Álvarez J. Ser persona y dignidad. Bilbao: Desclée de Brower; 2005.

11. Singer P. Ética práctica. Organización editorial de la Universidad de Cambridge; 1995.

12. Harris J. Superman y la mujer maravillosa. Madrid: Tecnos; 1998.

13. Espinoza E. Estatuto del embrión humano: aspectos científicos, éticos y antropológicos. Bioética. 2006: 4-8.

14. Pérez D. Evolución, desarrollo embrionario y psiquismo. Revista Latinoamericana de Bioética. 2009; 9(2): 116-123.

15. Pardo A. La determinación del comienzo de la vida humana: cuestiones de método. Cuadernos de Bioética 2007; XVIII(3): 335-345.

16. Habermas J. El futuro de la naturaleza humana. ¿Hacia una eugenesia liberal? Madrid: Paidós Ibérica; 2002.

17. López N. El cigoto de nuestra especie es cuerpo humano. Persona y Bioética 2010; 14(2): 120-140.

18. Zurriarían R. Utilitarismo ético en la investigación biomédica con embriones humanos. Persona y Bioética 2008; 12(030): 16-28.

19. López N, Fernández M, Santiago E. Selección de embriones humanos. Diagnóstico genético preimplantacional. Cuadernos de Bioética 2011; XXII(2): 243-258.

20. Valdéz M. Comentario a la ponencia de Evandro Agazzi. En: González J, (coord.) Dilemas de Bioética. México: Fondo de Cultura Económica; 2007.

21. Viesca C. Acerca del estado ontológico del embrión. En: González J, (coord.) Dilemas de Bioética. México: Fondo de Cultura Económica; 2007.

22. Bolivia. Código Civil. 1975. (Citado el 7 de diciembre de 2012). Disponible en: http://www.derechoteca.com/codigocivil-boliviano-1975.htm.

23. Costa Rica. Código Civil. 1988. (Citado el 7 de diciembre de 2012). Disponible en: http://www.cendeisss.sa.cr/etica/ codcivil.pdf.

24. Colombia. Código Civil. 2006. (Citado el 7 de diciembre de 2012). Disponible en: http://www.oas.org/dil/esp/Codigo_Civil_Colombia.pdf.

25. Honorable legislatura de la provincia de Buenos Aires. Ley 14.208, 2 de diciembre de 2010.

26. Congreso de Colombia. Proyecto de Ley No 45 del 2000.

27. México. Reglamento de la Ley General de Investigaciones, México 2012. (Citado el 7 de diciembre de 2012). Disponible en: http://www.salud.gob.mx/unidades/cdi/nom/compi/rlgsmis.html.

28. Vergé C. Genética y bioética en América Latina. Acta Bioethica 2004; 10(2): 155-166.

Recibido: 22 de enero de 2015

Aceptado: 4 de noviembre de 2015 